\title{
Population differentiation in female sex pheromone and male preferences in a solitary bee
}

\author{
Nicolas J. Vereecken • Jim Mant • Florian P. Schiestl
}

Received: 21 August 2006/Revised: 7 November 2006 / Accepted: 8 November 2006 / Published online: 19 December 2006

(C) Springer-Verlag 2006

\begin{abstract}
Population differentiation in female mating signals and associated male preferences can drive reproductive isolation among segregated populations. We tested this assumption by investigating intraspecific variation in female sex pheromone and associated male odour preferences among distant populations in the solitary bee Colletes cunicularius (L.) by using quantitative gas chromatography and by performing field bioassays with synthetic blends of key sex pheromone compounds. We found significant differences in sex pheromone blends among the bee populations, and the divergence in odour blends correlated positively with geographic distance, suggesting that genetic divergence among distant populations can affect sex pheromone chemistry. Our behavioural experiments, however, demonstrate that synthetic copies of allopatric female sex pheromones were cross-attractive to patrolling males from distant populations, making reproductive isolation by non-recognition of mating signals among populations unlikely. Our data also show that patrolling male bees from different populations preferred odour types from allopatric populations at the two sites of bioassays. These male preferences are not expected to select for changes in the female sex pheromone, but may influence the evolution of
\end{abstract}

Communicated by R. F. A. Moritz

N. J. Vereecken $(\bowtie)$

Behavioural and Evolutionary Ecology,

Free University of Brussels CP 160/12,

Avenue F.D. Roosevelt 50,

1050 Brussels, Belgium

e-mail: nicolas.vereeecken@ulb.ac.be

J. Mant - F. P. Schiestl

Plant Ecological Genetics, Institute for Integrative Biology,

ETH Zürich CHN, Universitätsstrasse 16,

CH-8092 Zurich, Switzerland floral odour in sexually deceptive orchids of the genus Ophrys that are pollinated by C. cunicularius males.

Keywords Colletes cunicularius .

Population differentiation - Odour preferences .

Ophrys orchids · Pollination by sexual deception

\section{Introduction}

Divergence in courtship signals has often been referred to as a prominent force promoting reproductive isolation among evolutionary lineages, which may ultimately lead to speciation (West-Eberhard 1983; Andersson 1994; Panhuis et al. 2001). The major mechanisms commonly raised for driving allopatric divergence in mating cues are (1) stochastic processes (Fisher 1930; Lande 1981) and (2) adaptation to local environments (see Boughman 2002 for a review). These evolutionary forces are not mutually exclusive and might even act in concert, thereby promoting adaptive population divergence over time (Schluter 2000). In spite of many reports on the nature of courtship signals across the animal kingdom, the extent to which population differentiation in mating cues affects species recognition has received little empirical support and remains a key issue in evolutionary biology (Andersson 1994).

Most solitary bee species display patchy distribution patterns throughout their range as an outcome of the spatial heterogeneity of their nesting sites and foraging resources (O’Toole 1994; Tscharntke and Brandl 2004)_which may include only particular floral rewards (oligolectism; Eickwort and Ginsberg 1980; Simpson and Neff 1981) - and an overall restricted ability to forage over great distances (see e.g. Gathmann and Tscharntke 2002). These constraints may restrict continuous gene flow among distant populations and 
thus lead to evolutionary divergence, especially under spatially varying selection regimes (Jordan 1905; Wright 1943; Antonovics 1971; Hedrick et al. 1976).

As in many insects, mate recognition in solitary bees is mediated by chemical cues, so-called sex pheromones (reviewed by Ayasse et al. 2001), although other mating cues can also be involved (e.g. Larsen et al. 1986; Candolin 2003). One of the few solitary bees for which sex pheromone data are available is Colletes cunicularius (L.), which can be found in early spring throughout the EuroSiberian region (Noskiewicz 1936) when few other solitary bee species are active (Michener 1974; Larsson and Tengö 1989; Mader 1999). The chemical basis to mate location and recognition by patrolling C. cunicularius males has recently been unravelled by Mant et al. (2005a), after earlier studies by Bergström and Tengö (1978), Cane and Tengö (1981) and Borg-Karlson et al. (2003). The speciesspecific mate attraction mechanism in C. cunicularius females has been shown to include, as an early step in the males' sexual stimulation and inspection flights, emission of the long-range $(>1 \mathrm{~m})$ attractant linalool (3,7-dimethyl1,6-octadien-3-ol; Borg-Karlson et al. 2003), a highly volatile and ubiquitous monoterpene alcohol (Knudsen et al. 1993; Raguso and Pichersky 1999; Knudsen and Gershenzon 2006). Subsequent short-range $(<10 \mathrm{~cm})$ mate attraction and copulation attempts are triggered by cuticular hydrocarbons (CHCs) located on the female body surface. A functional dissection of behaviourally active compounds identified by gas chromatography with electroantennographic detection, in addition to behavioural bioassays, has pinpointed a set of three (Z)-7 alkenes of 21, 23 and 25 carbons chain length as key compounds of the female sex pheromone in this bee species (Mant et al. 2005a).
To date, population variation (i.e. dialects) in female sex pheromone signals and associated preferences have only been reported from moths (see e.g. Klun et al. 1975; Miller and Roelofs 1980; Löfstedt et al. 1986; Hansson et al. 1990; Toth et al. 1992; Kawazu et al. 2000; McElfresh and Millar 2001) and from Drosophila flies (see e.g. Jallon and David 1987; Markow 1991; Stennett and Etges 1997; Etges and Ahrens 2001). In most cases, geographic isolation of populations along with genetic drift have been shown to foster the evolution of population-specific signals, usually consisting of quantitative "variation on a theme" (i.e. identical key sex pheromone compounds in different relative amounts; Löfstedt et al. 1986; Hansson et al. 1990; Toth et al. 1992; Löfstedt 1993). Field tests performed with synthetic blends of female sex pheromone compounds have demonstrated population differentiation in compound detection and odour preferences in male moths (see Hansson et al. 1990 and references therein; Toth et al. 1992). Although the topic of sex pheromone differentiation and its potential role in reproductive isolation and allopatric speciation is one of high interest in evolutionary ecology, very few studies have addressed this issue in hymenopterans, especially in solitary bees (reviewed by Ayasse et al. 2001).

In this study, we investigated differences in female mating signals in C. cunicularius by performing comparative chemical analyses of the female sex pheromone from five populations from Austria, France, Italy and Switzerland (Fig. 1). Additionally, we tested the hypothesis of population-specific odour preferences of $C$. cunicularius males by performing bioassays with synthetic imitations of population-specific blends of key compounds for mate attraction in two natural populations in Austria and Switzerland. Specifically, we ask the following questions: (1) Does the sex

Fig. 1 Sampling localities of $C$. cunicularius and Ophrys exaltata. The bees were sampled at Ondres-plage $(F)$, Neuhausen $(\mathrm{CH})$, Fussach $(A)$, Vienna $(A)$ and Monte Gargano (It). The sites of bioassays are underlined in black

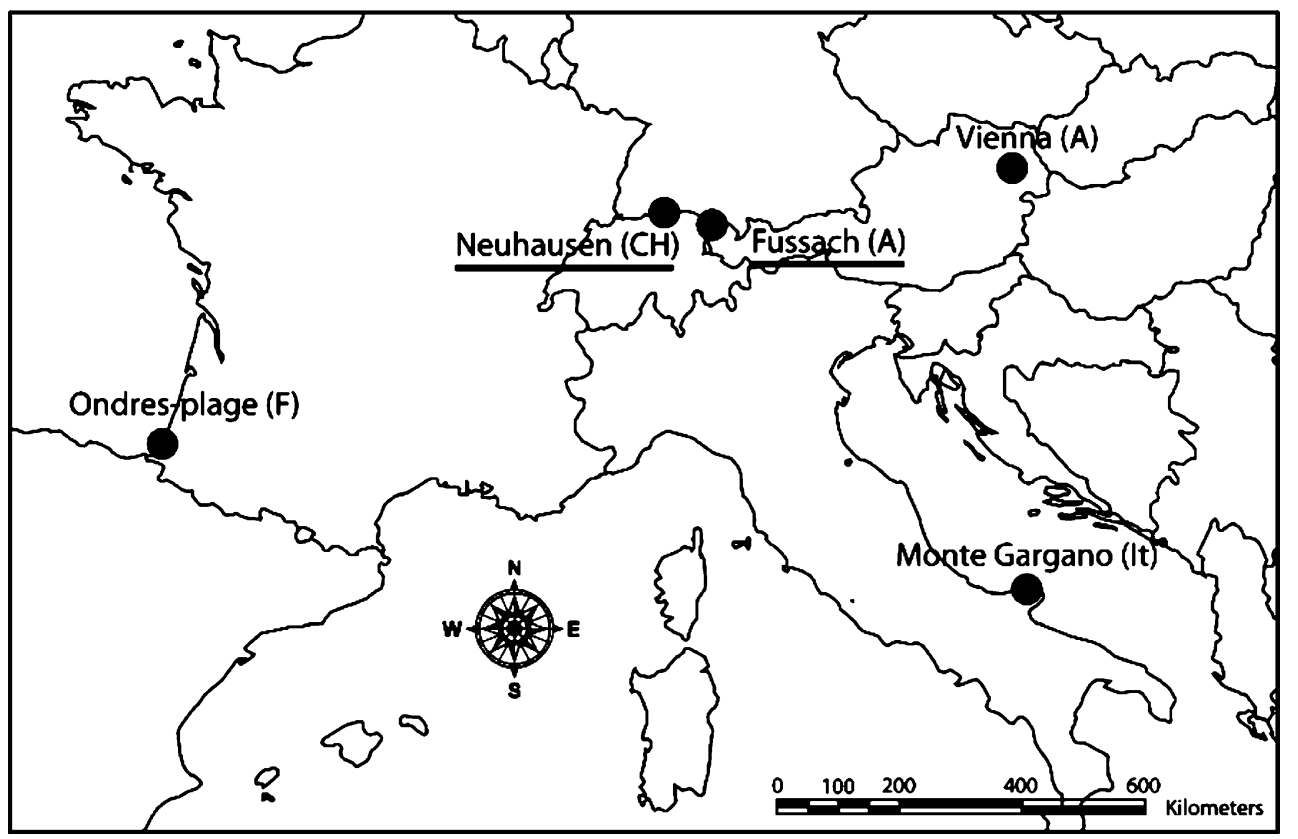


pheromone signal of $C$. cunicularius females vary among distant populations? (2) Do C. cunicularius males have population-specific odour preferences?

\section{Materials and methods}

Sample collection

Virgin C. cunicularius females were collected in early spring in geographically distant populations at Fussach (A; $n=33)$, Vienna (A; $n=12)$, Neuhausen $(\mathrm{CH} ; n=56)$, Ondres-plage (F; $n=20)$ and Monte Gargano (It; $n=16$; Fig. 1). Virgin females are easily detected after emergence when a cluster of sexually aroused males forms around them. All attractive $C$. cunicularius females were caught with a hand net, stored individually in chilled plastic cups (Eppendorfs) and instantaneously killed by freezing. Epicuticular waxes of the bees were sampled by extracting the body of individual female bees in $400 \mu$ l hexane (high performance liquid chromatography grade) for $1 \mathrm{~min}$. All extracts were stored at $-20^{\circ} \mathrm{C}$. Before GC analyses, $100 \mathrm{ng}$ $\mathrm{n}$-octadecane was added as internal standard to all samples.

\section{Chemical analyses}

All samples were analyzed by gas chromatography (GC) on a Hewlett Packard $6890 \mathrm{~N}$ GC equipped with a HP-5 capillary column $(30 \mathrm{~m} \times 0.32 \mathrm{~mm} \times 0.25 \mu \mathrm{m})$. The injector temperature was kept at $300^{\circ} \mathrm{C}$. One microlitre aliquots of the extracts was injected splitless at $50^{\circ} \mathrm{C}(1 \mathrm{~min})$ followed by a programmed increase of oven temperature to $300^{\circ} \mathrm{C}$ at a rate of $10^{\circ} \mathrm{C} / \mathrm{min}$; helium was used as the carrier gas. Compounds were identified by comparison of retention times with authentic standard compounds. Additionally, selected samples were analyzed with a GC with a mass selective detector (MSD Hewlett Packard G1800 A), and MS spectra compared with those of known reference substances (Mant et al. 2005a). The absolute amounts of the 40 identified compounds were calculated by the internal standard method as described by Mant et al. (2005a). Relative proportions (\%) were calculated by summing up the absolute amounts of all compounds; absolute amounts of individual compounds were then divided by the sum and multiplied by 100 .

Preparation of synthetic blends

The mean relative and absolute amounts of all compounds found in epicuticular extracts of $C$. cunicularius females (Table 1) were used to prepare three synthetic blends designed to mimic relative proportions of key sex pheromone compounds found in natural extracts of virgin $C$. cunicularius females from Fussach (A), Monte Gargano (It) and Neuhausen (CH; Table 2). Not all behaviourally active compounds (see Mant et al. 2005a) could be used to prepare the synthetic blends, as only 12 active compounds [including the major compounds for mate attraction described by Mant et al. (2005a)] were available to us in synthetic form. GC runs of the synthetic blends (synthetic compounds mixed with hexane) were made before bioassays to check the relative amounts of compounds in the blends. Each synthetic mixture tested contained equal absolute amounts of active compounds in different ratios (Table 3). This method allowed focusing on ascertaining the impact of individual hydrocarbon profiles (and not absolute amounts of compounds) on the short-range attractiveness of the blends towards mate-searching males.

\section{Behavioural experiments}

Bioassays were performed in late March and early April in natural populations at Fussach (A) and Neuhausen $(\mathrm{CH}$; Fig. 1) where thousands of $C$. cunicularius males were patrolling for emerging females on restricted nesting/ emergence sites. The density of bees in each site was stable over the days of observations, although higher at Neuhausen $(\mathrm{CH})$ than at Fussach (A). Behavioural responses of male bees towards dummies (black cylindrical

Table 1 Mean absolute amounts $(\mu \mathrm{g})$ of compounds recorded in natural extracts of individual virgin $C$. cunicularius females

\begin{tabular}{lllllll}
\hline & \multicolumn{5}{l}{ Natural extracts ${ }^{\mathrm{a}}$ (Mean absolute amounts in micrograms \pm SE) } \\
\cline { 2 - 7 } & Fussach (A) & Vienna (A) & Neuhausen (CH) & Ondres-plage (F) & Monte Gargano (It) & $\chi^{2}-F$ values \\
\hline All compounds & $3.776 \pm 1.697$ (a) & $3.854 \pm 3.031$ (a) & $8.542 \pm 3.477$ (b) & $2.604 \pm 0.816$ (c) & $10.724 \pm 3.563$ (d) & $18.888^{*}$ \\
Active compounds & $3.130 \pm 1.628$ (a) & $2.987 \pm 3.053$ (a) & $7.728 \pm 3.134$ (b) & $1.201 \pm 0.390$ (c) & $9.881 \pm 3.290$ (d) & $92.006^{* *}$ \\
Non-active compounds & $0.645 \pm 0.283$ (a) & $0.867 \pm 0.421$ (a) & $0.813 \pm 0.429$ (a) & $1.402 \pm 0.427$ (b) & $0.842 \pm 0.307$ (a) & $6.342^{* *}$ \\
\hline
\end{tabular}

Different letters inside the parentheses indicate significant differences.

${ }^{a}$ Pairwise comparisons among groups for each class of compounds (same line) using (1) non-parametric Mann-Whitney $U$-test (with Bonferroni correction for all compounds and active compounds, $\alpha=0.005)$ or (2) ANOVA post-hoc LSD test [for non-active compounds, $\alpha=0.005(d f=4)$ ]

${ }^{\mathrm{b}}$ Overall comparisons for each class of compounds (same line) using (1) non-parametric Kruskal-Wallis test (for all compounds and active compounds, $\alpha=0.05\left(d f=5 ; * P<0.05,{ }^{*} P<0.01\right)$ or (2) ANOVA (for non-active compounds, $\alpha=0.005(d f=4 ; * P<0.005, * * P<0.001)$ 
Table 2 Mean relative amounts (\%) of compounds recorded in cuticle extracts of individual virgin C. cunicularius females

Active compounds $\quad$ Natural extracts ${ }^{\mathrm{a}}$ (Mean relative amounts in $\% \pm \mathrm{SE}$ )

\begin{tabular}{lllll}
\hline Fussach (A) & Vienna (A) & Neuhausen (CH) & Ondres-plage (F) & Monte Gargano (It) $\chi^{2}$ Values \\
\end{tabular}

Alcohols

1. Linalool

Aldehydes and esters

2. Hexadecanal (and isopropyle) $0.350 \pm 0.039$ (a) $0.241 \pm 0.039$ (a) $0.532 \pm 0.033$ (b)

3. Eicosanal

4. Tetracosanal

5. Dodecyltetradecanoate

(and decylhexadecanoate)

Unsaturated hydrocarbons

$1.369 \pm 0.236(\mathrm{c}, \mathrm{e}) \quad 2.801 \pm 0.882(\mathrm{~d}, \mathrm{e})$

$29.859 * *$

6. (Z)-7-Heneicosene

7. (Z)-7-Tricosene

8. (Z)-7-Pentacosene

9. (Z)-9-Tricosene

10. (Z)-9-Tetracosene

11. (Z)-9-Pentacosene

12. (Z)-9-Heptacosene

13. (Z)-9-Nonacosene

14. Z-9-Hentriacontene

15. (Z)-8,(Z)-20-Nonacosadiene

16. (Z)-8,(Z)-20-Hentriacontadiene

17. (Z)-11-Nonacosene

Saturated hydrocarbons

18. Heneicosane

19. Tricosane

20. Pentacosane

21. Heptacosane

Unknown compound

22. A14

\section{$2.761 \pm 0.335$ (a)}

$2.419 \pm 0.310$ (a)

Non-active compounds

23. Dodecosane

24. Tetracosane

25. Hexacosane

26. Octacosane

27. Nonacosane

28. (Z)-3-Tricosene

29. (Z)-5-Tricosene

30. (Z)-5-Pentacosene

31. (Z)-7-Heptacosene

32. (Z)-7-Nonacosene

33. C-Unknown

34. D-Unknown

35. E-Unknown

36. F-Unknown

37. M-Unknown

38. S-Unknown

39. Y-Unknown

40. Z-Unknown
$0.891 \pm 0.076$ (a) $\quad 0.847 \pm 0.105$ (a,b) $1.070 \pm 0.042$ (b)

$0.168 \pm 0.055$ (a,d) $\quad 0.441 \pm 0.135$ (b) $\quad 0.106 \pm 0.014$ (a)

$0.297 \pm 0.061(\mathrm{a}, \mathrm{c}) \quad 0.468 \pm 0.222$ (a) $\quad 0.314 \pm 0.024$ (a) $1.673 \pm 0.286$ (a)

$2.091 \pm 0.235$ (a)

$1.878 \pm 0.612$ (a)

$0.311 \pm 0.063(\mathrm{a}, \mathrm{b})$

$7.425 \pm 1.069$ (a)

$4.006 \pm 0.390$ (a)

$5.323 \pm 0.455$ (a)

$2.323 \pm 0.299$ (a)

$0.597 \pm 0.105(\mathrm{a}, \mathrm{c})$

$1.010 \pm 0.334$ (a)

$1.533 \pm 0.751$ (b) $\quad 6.069 \pm 0.325$ (c) $1.113 \pm 0.576$ (a,b) $0.822 \pm 0.096$ (b) $2.310 \pm 1.143$ (b) $1.911 \pm 0.176$ (a)

$1.054 \pm 0.564$ (a) $2.385 \pm 0.336$ (b)

$0.494 \pm 0.253$ (a,b) $0.305 \pm 0.026$ (a)

$1.984 \pm 0.527$ (b) $8.966 \pm 0.684$ (a)

$2.938 \pm 0.647$ (a) $6.679 \pm 0.523$ (b)

$4.837 \pm 0.929$ (a) $\quad 4.602 \pm 0.317$ (a)

$2.219 \pm 0.483(\mathrm{a}, \mathrm{b}) 1.440 \pm 0.221(\mathrm{~b})$

$0.341 \pm 0.106(\mathrm{a}, \mathrm{e}) \quad 0.636 \pm 0.052$ (c)

$2.553 \pm 0.668$ (a) $2.456 \pm 0.176$ (a)

$1.523 \pm 0.445$ (b) $1.347 \pm 0.389$ (a)

$6.142 \pm 0.712$ (a) $\quad 3.911 \pm 0.747$ (b) $\quad 6.142 \pm 0.312$ (a)

$18.257 \pm 0.992$ (a) $11.755 \pm 1.188$ (b) $24.871 \pm 0.746$ (c) $21.621 \pm 0.951$ (d) $20.113 \pm 1.447$ (a,d) $8.677 \pm 0.421$ (a) $8.891 \pm 0.930$ (a) $11.279 \pm 0.450$ (b) $8.490 \pm 0.555$ (a) $10.053 \pm 0.935$ (a)

$5.869 \pm 0.326$ (a) $\quad 7.582 \pm 1.096$ (a) $\quad 6.650 \pm 0.344$ (a) $\quad 4.177 \pm 0.285$ (b) $\quad 3.660 \pm 0.347$ (b)

$0.035 \pm 0.019$ (a) $\quad 0.106 \pm 0.048$

$0.034 \pm 0.008$ (b)

$0.000 \pm 0.000(c) \quad 0.065 \pm 0.011(d)$ $(\mathrm{a}, \mathrm{b} ; \mathrm{c}, \mathrm{d})$

$0.019 \pm 0.015$ (c) $\quad 0.128 \pm 0.019$ (d) $0.425 \pm 0.037$ (c,d) $\quad 0.485 \pm 0.059$ (d) $0.000 \pm 0.000$ (c) $\quad 0.064 \pm 0.015$ (d) $0.012 \pm 0.008$ (b) $\quad 0.300 \pm 0.089$ (c)

$83.704 * *$ $30.404 * *$ $60.949 * *$ $47.281 * *$

$14.481 \pm 1.902$ (d) $5.828 \pm 1.215$ (c,e) $7.803 \pm 1.681$ (c) $\quad 5.202 \pm 1.349$ (c) $2.390 \pm 1.048(\mathrm{a}, \mathrm{b}) \quad 16.291 \pm 2.051(\mathrm{c})$ $6.754 \pm 1.759(\mathrm{a}, \mathrm{b}) \quad 1.128 \pm 0.445$ (a) $0.956 \pm 0.383(\mathrm{a}, \mathrm{b}) \quad 0.379 \pm 0.046(\mathrm{~b})$ $3.702 \pm 1.022$ (b) $9.693 \pm 1.309$ (a) $1.020 \pm 0.181$ (c) $3.785 \pm 1.079$ (a) $0.533 \pm 0.087$ (b) $\quad 0.720 \pm 0.117 \mathrm{c}$ (b) $0.373 \pm 0.060$ (c) $\quad 0.831 \pm 0.247$ (c) $0.000 \pm 0.000(\mathrm{~d}) \quad 0.312 \pm 0.082(\mathrm{e})$ $0.173 \pm 0.078$ (b) $\quad 0.887 \pm 0.302$ (c) $0.000 \pm 0.000$ (c) $\quad 1.478 \pm 0.398$ (b)

$62.468 * *$ $45.628 * *$ $32.566 * *$ $25.054 * *$ $8.210 *$ $34.990 * *$ $56.575 * *$ $39.545 * *$ 76.038 ** $58.964 * *$ $60.840 * *$ $60.111 * *$

$38.957 * *$ $49.764 * *$ $25.649 * *$ $40.408 * *$

$45.278 * *$

$0.435 \pm 0.027$ (a) $\quad 0.306 \pm 0.032$ (b) $0.478 \pm 0.014$ (a,d) $0.635 \pm 0.024$ (c) $0.687 \pm 0.177$ (d) $0.34 \pm 0.024$ (a) $\quad 0.339 \pm 0.042$ (a,b) $0.358 \pm 0.011$ (b) $0.348 \pm 0.022$ (a,b) $0.476 \pm 0.033$ (c) $1.162 \pm 0.450$ (a,c) $9.498 \pm 1.161$ (b) $0.274 \pm 0.014$ (a) $0.202 \pm 0.022$ (c) $0.217 \pm 0.017$ (c) $0.186 \pm 0.034$ (a) $\quad 0.198 \pm 0.060$ (a,b) $0.178 \pm 0.018$ (a) $0.079 \pm 0.027$ (b) $0.178 \pm 0.049$ (a) $3.128 \pm 0.208$ (a) $\quad 0.888 \pm 0.375$ (b) $2.754 \pm 0.189$ (a) $1.716 \pm 0.158$ (c) $1.672 \pm 0.208$ (c) $0.479 \pm 0.062$ (a) $\quad 0.397 \pm 0.080$ (a) $0.373 \pm 0.027$ (a) $0.824 \pm 0.066$ (b) $0.392 \pm 0.064$ (a) $0.426 \pm 0.075$ (a,d) $0.214 \pm 0.053$ (a,b) $0.211 \pm 0.015$ (b) $0.102 \pm 0.087$ (c) $0.399 \pm 0.058$ (d) $0.966 \pm 0.096$ (a) $\quad 0.679 \pm 0.138$ (a,b) $0.749 \pm 0.218$ (b) $0.333 \pm 0.056$ (c) $0.078 \pm 0.078$ (d) $1.921 \pm 0.297$ (a,c) $1.296 \pm 0.252$ (a) $1.490 \pm 0.152$ (a) $0.649 \pm 0.158$ (b) $2.366 \pm 0.339$ (c) $1.461 \pm 0.184$ (a) $3.103 \pm 0.537$ (b) $0.861 \pm 0.090$ (c) $0.377 \pm 0.067$ (d) $0.173 \pm 0.037$ (e) $0.016 \pm 0.011$ (a) $0.050 \pm 0.025$ (a) $0.053 \pm 0.010$ (b) $0.000 \pm 0.000$ (a) $0.117 \pm 0.027$ (c) $0.479 \pm 0.028$ (a) $\quad 0.448 \pm 0.059$ (a,c) $0.466 \pm 0.041$ (a,c) $0.793 \pm 0.080$ (b) $0.395 \pm 0.020$ (c) $0.210 \pm 0.020$ (a) $\quad 0.563 \pm 0.317$ (a,b) $0.237 \pm 0.018$ (a) $0.441 \pm 0.047$ (b) $0.277 \pm 0.051$ (a) $0.862 \pm 0.329$ (a) $\quad 1.389 \pm 0.369$ (b) $0.157 \pm 0.015$ (a) $0.000 \pm 0.000$ (c) $0.218 \pm 0.051$ (a) $3.001 \pm 0.452$ (a) $1.237 \pm 0.354$ (a) $0.143 \pm 0.011$ (b,d) $0.514 \pm 0.070$ (c) $0.224 \pm 0.054$ (d) $0.341 \pm 0.042$ (a,c) $1.597 \pm 1.170$ (a) $0.171 \pm 0.008$ (b,c) $0.403 \pm 0.066$ (a) $0.195 \pm 0.022$ (c) $0.367 \pm 0.048$ (a) $\quad 0.132 \pm 0.065$ (b) $0.394 \pm 0.023$ (a) $0.000 \pm 0.000$ (b) $0.293 \pm 0.042$ (a) $0.334 \pm 0.051$ (a) $\quad 0.463 \pm 0.201$ (a,b) $0.248 \pm 0.021$ (a) $0.543 \pm 0.068$ (b,c) $0.772 \pm 0.103$ (c)
$43.076 * *$ 17.507 * $38.820 * *$ 10.915 * $46.248 * *$ $29.574 * *$ $41.633 * *$ $52.890 * *$ $27.042 * *$ $73.489 * *$ $82.367 * *$ $27.822 * *$ 25.848 ** $57.105 * *$ $45.870 * *$ $34.047 * *$ $64.485 * *$ $36.825 * *$

Different letters inside the parentheses indicate significant differences.

${ }^{a}$ Pairwise comparisons among groups for each compound (same line) using non-parametric Mann-Whitney $U$-test, $\alpha=0.005$

${ }^{\mathrm{b}}$ Overall comparisons for each compound (same line) using non-parametric Kruskal-Wallis test, $\alpha=0.05(d f=4 ; * P<0.05, * * P<0.01)$ 
Table 3 Mean relative amounts (\%) of behaviourally active compounds in cuticle extracts of individual virgin C. cunicularius females vs synthetic blends used for the bioassays

\begin{tabular}{|c|c|c|c|c|c|c|}
\hline \multirow[t]{2}{*}{ Active compounds } & \multicolumn{2}{|l|}{ Fussach (A) } & \multicolumn{2}{|c|}{ Monte Gargano (It) } & \multicolumn{2}{|l|}{ Neuhausen $(\mathrm{CH})$} \\
\hline & Natural extract & Synthetic blend & Natural extract & Synthetic blend & Natural extract & Synthetic blend \\
\hline 1. (Z)-7-Heneicosene & 4.59 & 3.9 & 7.25 & 6.95 & 7.19 & 6.67 \\
\hline 2. Heneicosane & 9.63 & 11.64 & 6.62 & 8.59 & 7.09 & 7.9 \\
\hline 3. (Z)-9-Tricosene & 5.49 & 5.35 & 0.85 & 0.93 & 2.65 & 2.39 \\
\hline 4. (Z)-7-Tricosene & 1.73 & 7.21 & 6.85 & 7.47 & 1.06 & 1.22 \\
\hline 5. Tricosane & 28.1 & 29.82 & 24.32 & 25.96 & 30.89 & 31.3 \\
\hline 6. (Z)-9-Pentacosene & 16.33 & 13.91 & 12.75 & 10.32 & 10.71 & 11.42 \\
\hline 7. (Z)-7-Pentacosene & 3.49 & 3.15 & 20.14 & 17.2 & 2.41 & 2.81 \\
\hline 8. Pentacosane & 10.8 & 7.89 & 11.7 & 11.64 & 13.7 & 13.37 \\
\hline 9. (Z)-9-Heptacosene & 5.59 & 5.22 & 3.64 & 4.17 & 8.12 & 8.32 \\
\hline 10. Heptacosane & 5.73 & 5.24 & 4.12 & 4.95 & 7.87 & 8.48 \\
\hline 11. (Z)-9-Nonacosene & 5.35 & 4.53 & 0.83 & 1.07 & 5.5 & 4.57 \\
\hline 12. (Z)-8-(Z)-20-Hentriacontadiene & 3.18 & 2.12 & 0.95 & 0.73 & 2.8 & 1.54 \\
\hline Total $(\%)$ & 100 & 100 & 100 & 100 & 100 & 100 \\
\hline Sum of absolute amounts $(\mu \mathrm{g})$ & 2.897 & 2.5 & 9.054 & 2.5 & 7.423 & 2.5 \\
\hline
\end{tabular}

plastic beads, $4 \times 5 \mathrm{~mm}$, mounted on an insect pin) scented with synthetic blends were taped using a voice recorder during 3 min and classified into two categories: (1) number of approaches [hovering in front of the dummy at close range $(<10 \mathrm{~cm})$ without any contact with the odour source] and (2) number of contacts (from a short pounce to a copulation attempt with the scented dummy). Odour sources were presented individually for each test (i.e. each scented dummy was used only once). A female-equivalent amount of $2.5 \mu \mathrm{g}$ of each synthetic blend was applied on each dummy with a Hamilton glass syringe $(100 \mu \mathrm{l}$; see blend composition in Table 3). The dummy was then placed in a male patrolling area after the solvent had evaporated. Controls (dummies treated with solvent only and placed in a male patrolling area after the solvent had evaporated) were tested independently for their attractiveness after every 5th test. All bioassays were conducted between 10 A.M. and 3 P.M.-when C. cunicularius males' patrolling activity was at peak. As males of $C$. cunicularius have been shown to patrol fairly localized regions on the nesting/ emergence site (Peakall and Schiestl 2004), test spots were changed after each bioassay in both populations to test the responses of different males to synthetic odour blends.

\section{Statistical analyses}

Means and standard errors (SE) of absolute $(\mu \mathrm{g} / \mathrm{ml})$ and relative amounts (\%) of all identified compounds were calculated for all natural extracts. When transforming data did not yield normal distributions and variances were not homogeneous, we used a non-parametric Kruskal-Wallis
$(\mathrm{K}-\mathrm{W})$ test for multiple independent comparisons of absolute and relative amounts of compounds among bee populations. Mann-Whitney (M-W) U-tests were performed for a posteriori pairwise comparisons of (1) the total amounts of compounds and (2) relative amounts of each compound among populations. A standard Bonferroni correction was used for pairwise comparisons among bee populations; the level of significance $(\alpha)$ was set to $0.005(\alpha=0.05$ divided by the number of comparisons, i.e. $\alpha=0.005$ ).

Multivariate analyses of population variation in cuticular hydrocarbons (relative amounts, in \%) of C. cunicularius females were performed by canonical discriminant function (CDF) analysis, as the data did not contain significant outliers and given that this multivariate method is robust even when the homogeneity of variances assumption is not met (Brosius 2002). CDF analysis was performed with all behaviourally active compounds. To test for differences in male bee responses to synthetic blends, a one-way analysis of variance (ANOVA; with LSD post-hoc test) was used. All these statistical tests were performed with the SPSS 11.5 package (Brosius 2002).

The spatial structuring of the female sex pheromone in C. cunicularius was investigated by performing a Mantel (1967) test, as implemented in GenAlEx 6 (Peakall and Smouse 2005a,b) based on individual-by-individual Euclidean distances in relative amounts of chemical compounds vs geographical distance among populations. Random permutations $(n=99)$ were used to test for significant correlation between divergence in odour compound profiles (active compounds) and geographical distance among sample populations. 


\section{Results}

Odour differences among bee populations

Our results show that all natural extracts of virgin $C$. cunicularius females of each population investigated contained all 40 odour compounds identified by Mant et al. (2005a). Overall significant differences were found among $C$. cunicularius populations in absolute amounts of (1) sum of all compounds (K-W test, $P<0.005$ ), (2) sum of active compounds sensu Mant et al. (2005a) (K-W tests, $P$ $<0.005$ ) and (3) sum of non-active compounds (ANOVA $\left.F_{(4,132)}=6.342, P=0.0001\right)$. Within all populations, except Ondres-plage (F), significantly higher absolute amounts of behaviourally active compounds were found compared to non-active compounds (Table 1).

A CDF analysis performed with all behaviourally active cuticular hydrocarbons recorded in solvent extracts of attractive $C$. cunicularius females allowed us to resolve the five bee populations into weakly overlapping groups (Fig. 2). This CDF analysis rejects the null hypothesis of homogeneity of covariance matrices (Box's $M=538.135$, $P<0.001$; small Wilks' $\lambda$ values: $\mathrm{W} \lambda 1=0.025$; $\mathrm{W} \lambda 2=0.115$ and associated $P 1$ and $P 2<0.001)$. The high discriminatory ability of the canonical discriminant functions 1 and 2 (plotted in Fig. 2) provides evidence for the importance of the independent variables (i.e. all behaviourally active odour compounds, including compounds 6-8 in Table 2) to the discriminant analysis. Canonical correlation values close to $1(\mathrm{Cc} 1=0.884 ; \mathrm{Cc} 2=0.822)$ associated with the two CDFs plotted in Fig. 2 further account for the significant contribution of the first two canonical discriminant functions to the resolving of all five $C$. cunicularius populations into weakly overlapping groups. The two CDFs plotted in Fig. 2 account for $76.4 \%$ of the overall variance among groups, which further indicates their great discriminatory ability in the model $(81.0 \%$ of cross-validated grouped cases were correctly classified). Overall, more than $50 \%$ of all cross-validated samples were assigned correctly to their population by the two CDFs [Fussach (A), 51.5\%; Vienna (A), 50.1\%; Neuhausen, 98.2\%; Ondres-plage, 85\%; Monte Gargano, $81.3 \%$ ].

A Mantel test performed with all active compounds revealed a significant positive correlation between divergence in chemical compounds profiles and geographical distance among populations $(y=0.0001 x+0.1649 ; P<0.05$; $r=0.654$; Fig. 3).

\section{Behavioural experiments}

Results from bioassays carried out at Fussach (A) and Neuhausen (CH; Fig. 1) indicate that male bees from both the Austrian and the Swiss populations were able to discriminate between the three synthetic odour blends with different relative amounts of behaviourally active cuticular hydrocarbons (Fig. 4). We also found that the three synthetic blends triggered different levels of attraction in C. cunicularius males and that synthetic blends designed to mimic sex pheromones from allopatric populations were significantly more attractive to patrolling males than synthetic copies of sympatric sex pheromones at both sites of bioassays [i.e. the Fussach (A) and Monte Gargano (It)
Fig. 2 Population differentiation in cuticular hydrocarbons in virgin C. cunicularius females. Canonical discriminant function $(C D F)$ plot of all behaviourally active compounds (relative proportions, in \%) found in epicuticular extracts of the female bees. Functions 1 and 2 account for $76.4 \%$ (48.4 and $28.0 \%$, respectively) of the total variability among populations

\section{Canonical Discriminant Function analysis}

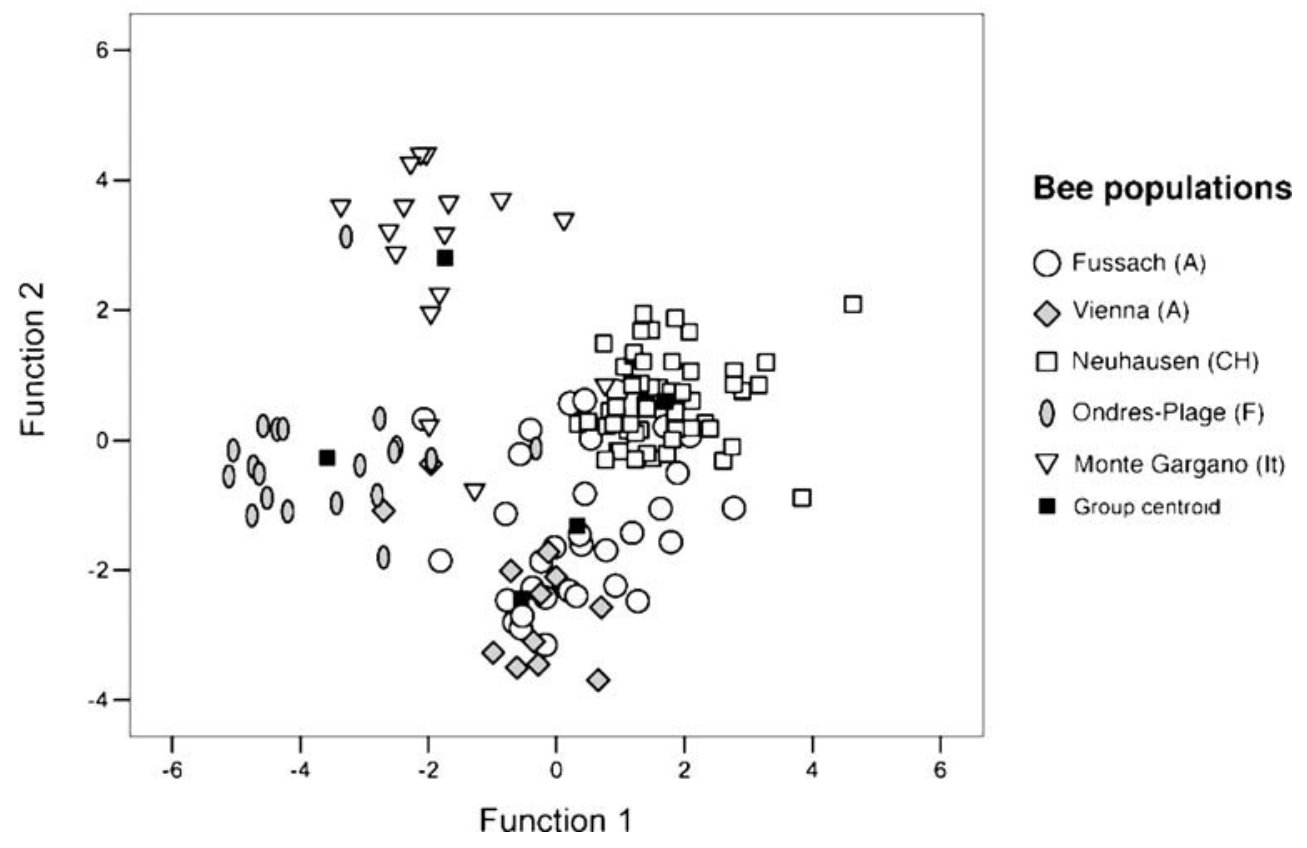


blends were significantly more attractive than the Neuhausen $(\mathrm{CH})$ blend at Neuhausen $(\mathrm{CH})$, whereas the Monte Gargano (It) and the Neuhausen $(\mathrm{CH})$ blends were significantly more attractive than the Fussach (A) blend at Fussach (A)] (Fig. 3). The differences in total responses between the two sites of bioassays are due to the higher bee density in Neuhausen $(\mathrm{CH})$ than Fussach (A).

\section{Discussion}

Sex pheromone "dialects"

In this paper, we report "dialects" in both absolute and relative amounts of compounds of the female sex pheromone in the wild bee $C$. cunicularius. Multivariate analyses performed with relative amounts of behaviourally active compounds identified in solvent extracts of virgin $C$. cunicularius females allowed us to place the five populations sampled into weakly overlapping clusters (i.e. population-specific dialects) within a multidimensional "olfactory landscape" (Fig. 2). Similar cases of sex pheromone dialects have been found in the turnip moth Agrotis segetum, for which females from segregated populations use population-specific blends consisting of different relative amounts of the same behaviourally active compounds (see e.g. Löfstedt et al. 1986; Hansson et al. 1990; Toth et al. 1992). In Drosphila mojavensis, where cuticular hydrocarbons are involved in mate recognition, Stennet and Etges (1997) and Etges and Ahrens (2001) have provided evidence for populationspecific patterns of long-chain cuticular hydrocarbons. Collectively, these results suggest that polymorphism in sex pheromone systems among segregated populations might concern a wide array of insect taxa.

Our results also show significant spatial structure in the female sex pheromone in this bee species, i.e. that odour samples from neighbouring populations, presumably encompassing the genetically most similar individuals, cluster together in the olfactory landscape (Figs. 2 and 3). Although this finding strongly suggests isolation-by-distance and a prevalent genetic basis of differences in patterns of behaviourally active compounds, the impact of environmental components such as changes in larval rearing substrates on variation in chemical signals cannot be ruled out a priori. Indeed, persuasive fits between shifts in larval diet and the resulting differences in cuticular hydrocarbon profiles in adults have already been documented in ants (see e.g. Liang and Silverman 2000) and in Drosophila (see e.g. Jallon and David 1987; Markow and Toolson 1990; Stennett and Etges 1997) where changes in CHC profiles have been shown to affect dramatically species recognition and, in some cases, to result in premating isolation among lineages adapted to different foraging resources (Koepfer 1987a,b; Etges 1992;
Etges and Ahrens 2001). The genetic basis of population differences in sex pheromone signals has, however, been recently supported by Watts et al. (2005) in the tropical fly Lutzomyia longipalpis. These authors combined data on sex pheromone chemistry and phylogeography from multiple populations and showed that spatial genetic structure was detected and that increased genetic differences among populations were positively correlated with increased differences in sex pheromone chemistry. Likewise, analyses performed by Dapporto et al. (2004) on CHC profiles in the paper wasp Polistes dominulus have shown that island and mainland populations sampled in the Tyrrhenian region formed separate clusters. As suggested by Dapporto et al. (2004), part of the explanation for this finding could be that the similarities in proportions of CHCs might reflect the closer genetic relatedness among individuals inhabiting populations of islands vs the mainland. In C. cunicularius, future studies on genetic structure of populations and their relatedness may help to elucidate whether population differentiation in sex pheromones are primarily determined by genetic and/or environmental factors.

\section{Odour preferences in C. cunicularius males}

It has long been argued that population divergence in secondary sex traits and associated mate preferences has the potential to lead to the establishment and evolution of pre-zygotic isolating barriers among segregated populations (Andersson 1994; West-Eberhard 1983). For example, in Drosophila mojavensis, premating isolation has been described as a consequence of significant differentiation in both courtship (chemical) signals and mate preferences for these traits among populations (Krebs and Markow 1989; Etges 1992). Similarly, Roelofs et al. (2002) have demonstrated the occurrence of shifts in the structure of sex pheromone components in Ostrinia moths. Along with the existence of rare males that might track these changes and respond to the new pheromone blend, such changes may lead to the evolution of an Ostrinia species with distinct sex pheromone signal.

Our study shows that patrolling C. cunicularius males from both sites of bioassays perceive subtle differences

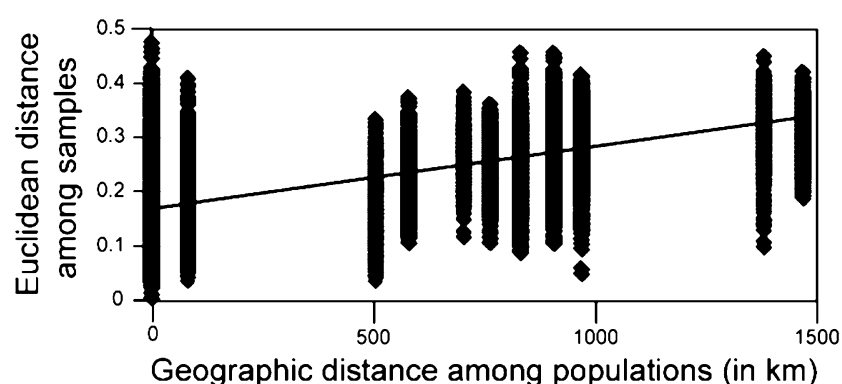

Fig. 3 Mantel's correlogram of Euclidean distance among chemical samples in active compounds plotted by spatial distance among sample sites (Mantel's $r=0.654 ; P<0.05$ with 99 permutations) 
among odour samples that consist of identical key compounds but differ in relative amounts (Fig. 4), a phenomenon that was already shown in other non-Apis bees such as Andrena nigroaenea (Schiestl and Ayasse 2000), Lasioglossum malachurum (Ayasse et al. 1999) and Osmia rufa (Ayasse and Dutzler 1998; Ayasse et al. 2000). Our study provides a multiple-population comparison of male odour preferences in a solitary bee and shows that patrolling $C$. cunicularius males are attracted to sex pheromone dialects from "exotic" (i.e. allopatric) populations, which suggests the sharing of mate recognition cues (sensu Paterson 1985) among segregated populations in this solitary bee species.

Many studies on sexual selection have largely documented that individuals often recognize and prefer to mate with individuals from "local" (or proximate) vs "exotic" populations (see e.g. Andersson 1994 and references therein; Boake 2002; Wong et al. 2004 and references therein). By contrast, our bioassays show that patrolling $C$. cunicularius males prefer odour types different from those found in their own population (i.e. "exotic" sex pheromones). We suggest two explanations for this "exotic effect": (1) As C. cunicularius is a gregarious solitary bee for which males search for mates in a restricted area of their nesting/emergence site (Peakall and Schiestl 2004), preferences for "exotic" pheromone signals in patrolling males may be innate and promote outbreeding by avoiding sibling mating, should the opportunity arise. The recourse to odour-based preferences for females to which males are probably less related has rarely been found before in bees (but see Smith and Ayasse 1987; Smith and Breed 1995), yet other similar cases have been found in flies (reviewed by Boake 2002), female crickets (Simmons 1989) as well as in mammals (Potts and Wakeland 1993; Clarke and Faulkes 1999), where it has also been advocated that such instances of odour-based mate choosiness might mirror optimal outbreeding. (2) Alternatively, odour-based discrimination may reflect learning abilities of patrolling $C$. cunicularius males, which prefer odour cues dissimilar to those they have encountered during earlier mating attempts (e.g. Wcislo 1992 and references therein; Ayasse et al. 2000). Under strong male-male competition for access to emerging, virgin females and given that females in this solitary bee species are monandrous (Bergström and Tengö 1978), such odour preferences might help to avoid futile mating attempts by successively directing males towards virgin females they have not yet encountered.

Collectively, as our results show, population divergence in female mating signals and associated male preferences in $C$. cunicularius is unlikely to lead to speciation (i.e. premating isolation by non-recognition of female secondary sex traits), as synthetic copies of allopatric female mating signals were shown to be cross-attractive to patrolling C. cunicularius males from distant populations (Fig. 4). Besides, the odour preferences for "exotic" blends found in males of $C$. cunicularius (Fig. 4) are unlikely to select for extreme deviation from the median female sex pheromone blend

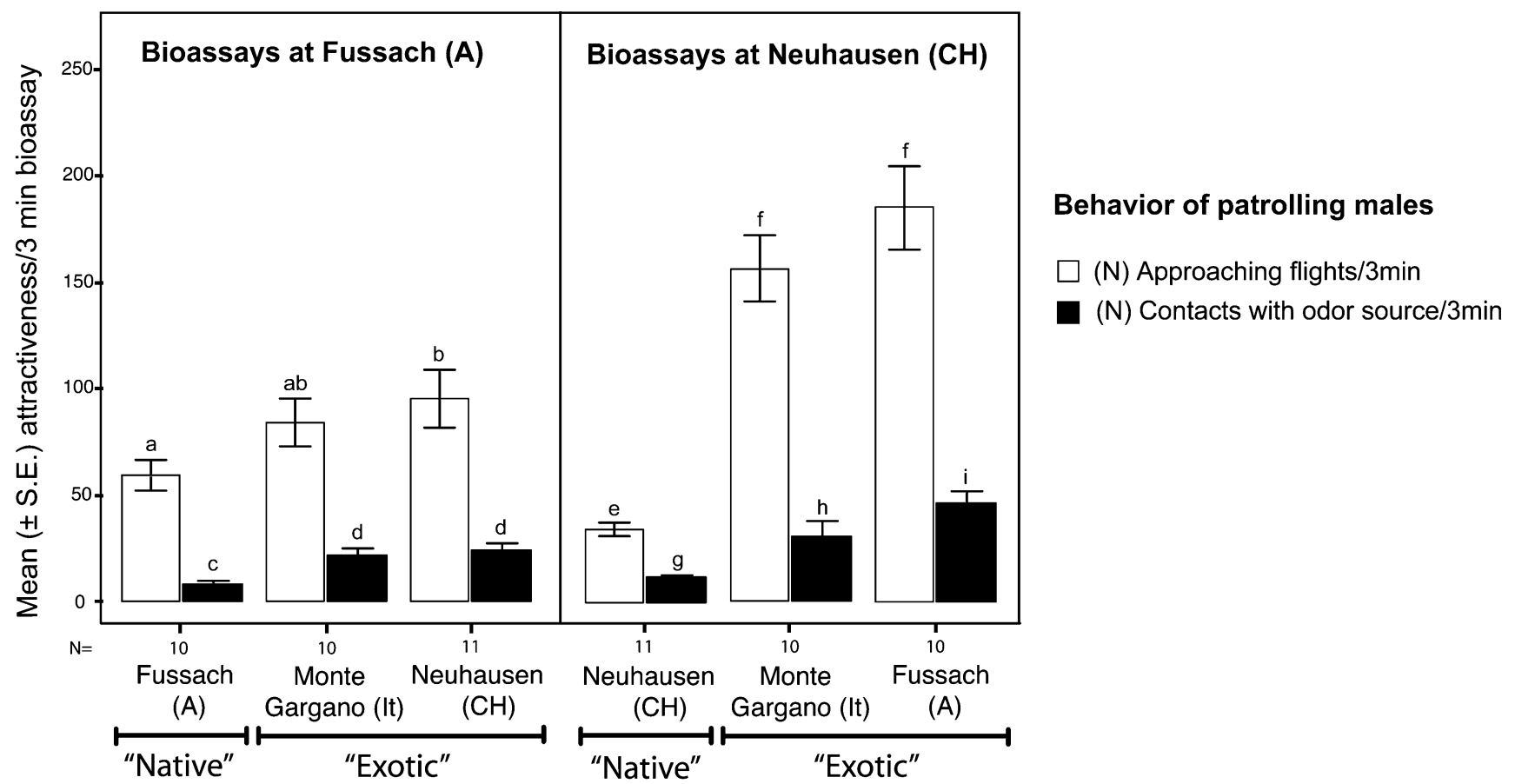

Fig. 4 Comparative level of attractiveness of the synthetic sex pheromone trio [Fussach $(A)$, Monte Gargano (It) and Neuhausen $(\mathrm{CH})]$ when assayed individually at Fussach $(A$, left $)$ and Neuhausen $(\mathrm{CH}, \mathrm{right})$ on patrolling males of $\mathrm{C}$. cunicularius. One-way ANOVA

with LSD post-hoc test $(\alpha=0.05)$. Different superscript letters on top of error bars indicate significant differences; the number of replicates are listed underneath the columns 
within populations because females are the limiting sex and hence, little subjected to male-mediated selection. However, mate preferences in male bees such as those reported here for C. cunicularius might transfer into selection on floral traits in those orchids that imitate mating signals of female hymenopterans for pollination and that are limited in their reproductive success by access to pollinators (see e.g. Schiestl 2004).

\section{Evolutionary implications for Colletes-Ophrys mimicry systems}

Insect communication signals are sometimes imitated by other organisms, which exploit the behaviour of the duped species (Dettner and Liepert 1994; Maynard Smith and Harper 2003 and references therein). A well-known case of this sort involves orchids of the genus Ophrys whose flowers mimic chemical, visual and tactile stimuli of virgin female bees (the model) and are pollinated exclusively by sexually aroused males of the respective species (the dupe or operator; reviewed by Schiestl 2005). Among the puzzling diversity of Ophrys species specialized on different pollinator species, at least four Ophrys species have evolved to mimic $C$. cunicularius mating cues (Mant et al. 2005b and references therein). One of them is Ophrys exaltata Tenore, which emits a species-specific floral odour blend consisting of compounds identical to those employed by $C$. cunicularius females to attract their mate (Mant et al. 2005a). In this orchid species, population differentiation in the floral odour was found to be stronger in floral odour compounds involved in pollinator attraction (active compounds) as compared to non-active compounds (Mant et al. 2005b), which implied pollinator-imposed selection mediated by population-specific preferences of male bees for mating cues. Our study demonstrates population-specific preferences of pollinators, the requirement for such a scenario, and thus supports the findings of Mant et al. (2005b).

Although it is often predicted for Batesian mimicry systems that mimics (i.e. orchids) are selected for signal refinement to optimally match the signal emitted by their model (i.e. virgin female bees; Fisher 1930; Turner 1988 and references therein; Stowe 1988), our finding of an "exotic effect" predicts that the orchids should evolve "exotic" odour bouquets (yet remaining within the boundaries of the communication channel to ensure attractiveness to the male pollinators), which slightly differ from the female bees within populations, and thus, be preferred by $C$. cunicularius males. These differences between orchid and female bee signals might, however, only be detectable through multivariate comparisons of orchid odour and female sex pheromone, using large sample sizes, which has not been employed in any orchid-pollinator study so far. We are currently investigating odour bouquets of orchids and virgin female bees from multiple populations to test, at the population scale, whether population differentiation in male bee preferences drives associated divergence in odour between female bees and the Ophrys species they pollinate.

Acknowledgement We sincerely thank C. Schulz and W. Francke (University of Hamburg, Germany) for providing us with synthetic compounds. J. Alcock (Arizona State University, USA) is gratefully acknowledged for having provided helpful comments on an earlier version of the manuscript. D. Genoud (Tarnos, France), G. Mahé (Saint-Nazaire, France), C.E. Hermosilla (La Rioja, Spain), G. Hölzler (Vienna, Austria) and A. Müller (ETH Zürich, Switzerland) shall also be warmly thanked for their useful help in collecting specimens. G. Caruso (Cambridge University, UK) provided us with generous help for the preparation of Fig. 1. We thank two anonymous referees for their valuable comments. The experiments comply with the current laws of the country in which they were performed. NJV was financially supported by the Belgian "Fonds pour la formation à la Recherche dans l'Industrie et l'Agriculture" (F.R.I.A.) and by a "Directeur Moiny" studentship delivered by the Order of Leopold ASBL (Belgium); JM and FPS were funded by the Swiss National Fund (SNF; project 3100-0681).

\section{References}

Andersson M (1994) Sexual selection. Monographs in behaviour and ecology. Princeton University Press, USA

Antonovics J (1971) The effects of a heterogeneous environment on the genetics of natural populations. Am Sci 59:593-599

Ayasse M, Dutzler G (1998) The function of pheromones in the mating biology of Osmia bees (Hymenoptera: Megachilidae). Social insects at the turn of the millenium. Proceedings of the 13th International Congress IUSSI, Adelaide, Australia. Flinders University Press, p 42

Ayasse M, Engels W, Lübke G, Taghizadeh T, Francke W (1999) Mating expenditures reduced via female sex pheromone modulation in the primitively eusocial halictine bee, Lasioglossum (Evylaeus) malachurum (Hymenoptera: Halictidae). Behav Ecol Sociobiol 45:95-106

Ayasse M, Dutzler G, Schiestl FP, Ibarra F, Francke W (2000) Identification of female and male sex pheromone in the solitary bee Osmia rufa (Hymenoptera: Megachilidae). International Congress of Entomology, Chemistry and Physiological Ecology Symposium and Poster Session, Brazil, Abstract Book II, p 21

Ayasse M, Paxton R, Tengö J (2001) Mating behaviour and chemical communication in the order Hymenoptera. Annu Rev Entomol 46:31-78

Bergström G, Tengö J (1978) Linalool in mandibular gland secretion of Colletes bees (Hymenoptera: Apoidea). J Chem Ecol 4:447449

Boake CRB (2002) Sexual signaling and speciation, a microevolutionary perspective. Genetica 116:205-214

Borg-Karlson A-K, Tengö J, Valterova I, Unelius CR, Taghizadeh T, Tolasch T, Francke W (2003) (S)-(+)-linalool, a mate attractant pheromone component in the bee Colletes cunicularius. J Chem Ecol 29:1-14

Boughman JW (2002) How sensory drive can promote speciation. Trends Ecol Evol 17:571-577

Brosius F (2002) SPSS Version 11. Mitp-Verlag, Bonn, Germany

Candolin U (2003) The use of multiple cues in mate choice. Biol Rev $78: 575-595$

Cane JH, Tengö J (1981) Pheromonal cues direct mate seeking behaviour of male Colletes cunicularius (Hymenoptera, Colletidae). J Chem Ecol 7:427-436 
Clarke FM, Faulkes CG (1999) Kin discrimination and female mate choice in the naked mole-rat Heterocephalus glaber. Proc R Soc Lond B 266:1995-2002

Dapporto L, Palagi E, Turillazzi S (2004) Cuticular hydrocarbons of Polistes dominulus as a biogeographic tool: a study of populations from the Tuscan Archipelago and surrounding areas. J Chem Ecol 30:2139-2151

Dettner K, Liepert C (1994) Chemical mimicry and camouflage. Annu Rev Entomol 39:129-154

Eickwort GC, Ginsberg HS (1980) Foraging and mating behaviour in Apoidea. Annu Rev Entomol 25:421-446

Etges WJ (1992) Premating isolation is determined by larval substrates in cactophilic Drosophila mojavensis. Evolution 46:1945-1950

Etges WJ, Ahrens MA (2001) Premating isolation is determined by larval rearing substrates in cactophilic Drosophila mojavensis. V. Deep geographic variation in epicuticular hydrocarbons among isolated populations. Am Nat 158:585-598

Fisher RA (1930) The genetical theory of natural selection. Clarendon Press, Oxford

Gathmann A, Tscharntke T (2002) Foraging ranges of solitary bees. J Anim Ecol 71:757-764

Hansson BS, Toth M, Löfstedt C, Szöcs G, Subchev M, Löfqvist J (1990) Pheromone variation among eastern European and a western Asian population of the turnip moth Agrotis segetum. J Chem Ecol 16:1611-1622

Hedrick PW, Ginevan ME, Ewing EP (1976) Genetic polymorphism in heterogeneous environments. Ann Rev Ecolog Syst 7:1-32

Jallon J-M, David JR (1987) Variations in cuticular hydrocarbons among the eight species of the Drosophila melaonogaster subgroup. Evolution 41:294-302

Jordan DS (1905) The origin of species through isolation. Science 22:545-562

Kawazu K, Hasegawa J-I, Honda H, Ishikawa Y, Wakamura S, Sugie H, Kamiwada H, Kamimuro T, Yoshiyasu Y, Tatsuki S (2000) Geographical variation in female sex pheromones of the rice leaffolder moth, Cnaphalocrocis medinalis: identification of pheromone components in Japan. Entomol Exp Appl 96:103109

Klun JA, Anglade PL, Baca F, Chapman OL, Chiang HC, Danielson DM, Faber W, Fels P, Hill RE, Hudon M, Kania CS, Keaster AJ et al (1975) Insect sex pheromones: intraspecific pheromone variability of Ostrinia nubilalis in North America and Europe. Environ Entomol 4:891-894

Knudsen JT, Gershenzon J (2006) The chemical diversity of floral scent. In: Dudareva NA, Pichersky E (eds) Biology of floral scent. Taylor and Francis Group, Boca Raton, USA, pp 27-52

Knudsen JT, Tollsten L, Bergström LG (1993) Floral scents-a checklist of volatile compounds isolated by head-space techniques. Phytochemistry 33:253-280

Koepfer HR (1987a) Selection for sexual isolation between geographic forms of Drosophila mojavensis. I. Interactions between the selected forms. Evolution 41:37-48

Koepfer HR (1987b) Selection for sexual isolation between geographic forms of Drosophila mojavensis. II. Effects of selection on mating preference and propensity. Evolution 41:1409-1413

Krebs RA, Markow TA (1989) Courtship behaviour and control of reproductive isolation in Drosophila mojavensis. Evolution 43:908-912

Lande R (1981) Models of speciation by sexual selection on polygenic traits. Proc Natl Acad Sci USA 78:3721-3725

Larsen O, Gleffe G, Tengö J (1986) Vibration and sound communication in solitary bees and wasps. Physiol Entomol 11:287-296

Larsson FK, Tengö J (1989) The effects of temperature and body size on the mating pattern of a gregariously nesting bee, Colletes cunicularius (Hymenoptera: Colletidae). Ecol Entomol 14:279-286
Liang D, Silverman J (2000) "You are what you eat": diet modifies cuticular hydrocarbons and nestmate recognition in the Argentine ant, Linepithema humile. Naturwissenschaften 87:412-416

Löfstedt C (1993) Moth pheromone genetics and evolution. Philos Trans R Soc Lond B 340:167-177

Löfstedt C, Löfqvist J, Lanne BS, Van Der Pers JNC, Hansson BS (1986) Pheromone dialects in European turnip moths Agrotis segetum. Oikos 46:250-257

Mader D (1999) Geologische und biologische Entomoökologie der rezenten Seidenbiene Colletes. Logabook, Köln

Mant JG, Brändli C, Vereecken NJ, Schulz CM, Francke W, Schiestl FP (2005a) Cuticular hydrocarbons as sex pheromone in Colletes cunicularius (Hymenoptera: Colletidae) and the key to its mimicry by the sexually deceptive orchid Ophrys exaltata (Orchidaceae). J Chem Ecol 31:1765-1787

Mant JG, Peakall R, Schiestl FP (2005b) Does selection on floral odor promote differentiation among populations and species of the sexually deceptive orchid genus Ophrys? Evolution 59:1449-1463

Mantel N (1967) The detection of disease clustering and a generalized regression approach. Cancer Res 27:209-220

Markow TA (1991) Sexual isolation among populations of Drosophila mojavensis. Evolution 45:1525-1529

Markow TA, Toolson EC (1990) Temperature effects on epicuticular hydrocarbons and sexual isolation in Drosophila mojavensis. In: Barker JSF, Starmer WT, MacIntyre RJ (eds) Ecological and evolutionary genetics of Drosophila. Monographs in evolutionary biology. Plenum, New York, pp 315-331

Maynard Smith J, Harper D (2003) Animal signals. Oxford series in ecology and evolution. Oxford University Press, USA

McElfresh JS, Millar JG (2001) Geographic variation in the pheromone system of the saturniid moth Hemileuca eglanterina. Ecology 82:3505-3518

Michener CD (1974) The social behaviour of the bees. Harvard University Press, Cambridge, MA

Miller JR, Roelofs WL (1980) Individual variation in sex pheromone component ratios in two populations of the redbanded leafroller moth, Argyrotaenia velutinana. Environ Entomol 9:359-363

Noskiewicz J (1936) Die Palearktischen Colletes-Arten. Prace Naukowe, Lwowie

O'Toole C (1994) Who cares for solitary bees? In: Matheson A (ed) Forage for bees in an agricultural landscape. International Bee Research Association, Cardiff, pp 47-56

Panhuis TM, Butlin R, Zuk M, Tregenza T (2001) Sexual selection and speciation. Trends Ecol Evol 16:364-371

Paterson HEH (1985) The recognition concept of species. In: Vrba ES (ed) Species and speciation. Transvaal Museum Monograph No.4, Pretoria, pp 21-29

Peakall R, Schiestl FP (2004) A mark-recapture study of male Colletes cunicularius bees: implications for pollination by sexual deception. Behav Ecol Sociobiol 56:579-584

Peakall R, Smouse PE (2005a) GenAlEx 6: Genetic analysis in Excel. Population genetic software for teaching and research. The Australian National University, Canberra, Australia. Available online at http://www.anu.edu.au/BoZo/GenAlEx/

Peakall R, Smouse PE (2005b) GenAlEx 6: genetic analysis in excel. Population genetic software for teaching and research. Mol Ecol Notes 6:288-295

Potts WK, Wakeland EK (1993) Evolution of MHC genetic diversitya tale of incest, pestilence and sexual preference. Trends Genet 9:408-412

Raguso RA, Pichersky E (1999) A day in the life of the linalool molecule: chemical communication in a plant-pollinator system. Part 1: linalool biosynthesis in flowering plants. Plant Species Biol 14:95-120

Roelofs WL, Liu W, Hao G, Jiao H, Rooney AP, Linn CE Jr (2002) Evolution of moth sex pheromones via ancestral genes. Proc Natl Acad Sci USA 99:13621-13626 
Schiestl FP (2004) Floral evolution and pollinator mate choice in a sexually deceptive orchid. J Evol Biol 17:67-75

Schiestl FP (2005) On the success of a swindle: pollination by deception in orchids. Naturwissenschaften 92:255-264

Schiestl FP, Ayasse M (2000) Post-mating odour in females of the solitary bee, Andrena nigroaenea (Apoidea, Andrenidae), inhibits male mating behaviour. Behav Ecol Sociobiol 48:303-307

Schluter D (2000) The ecology of adaptive radiation. Oxford series in ecology and evolution. Oxford University Press, New York

Simmons LW (1989) Kin recognition and its influence on mating preferences of the field cricket, Gryllus bimaculatus (Degeer). Anim Behav 38:68-77

Simpson BB, Neff JL (1981) Floral rewards: alternative to pollen and nectar. Ann Mo Bot Gard 68:301-322

Smith BH, Ayasse M (1987) Kin-based male mating preferences in two species of halictine bees. Behav Ecol Sociobiol 20:313318

Smith BH, Breed MD (1995) The chemical basis for nest-mate recognition and mate discrimination in social insects. In: Cardé RT, Bell WJ (eds) Chemical ecology of insects 2. Chapman \& Hall, London, pp 287-317

Stennett MD, Etges WJ (1997) Pre-mating isolation is determined by larval rearing substrates in cactophilic Drosophila mojavensis. III. Epicuticular hydrocarbon variation is determined by use of different host plants in Drosophila mojavensis and Drosophila arizonae. J Chem Ecol 23:2803-2824

Stowe MK (1988) Chemical mimicry. In: Spencer KC (ed) Chemical mediation of coevolution. Academic, London, pp 513-580
Toth M, Löfstedt C, Blair BW, Cabello T, Farag AI, Hansson BS, Kovalev BG, Maini S, Nesterov EA, Pajor I, Sazanov AP, Shamshev IV, Subchev M, Szöcs G (1992) Attraction of male turnip moths Agrotis segetum (Lepidoptera: Noctuidae) to sex pheromone components and their mixtures at 11 sites in Europe, Asia, and Africa. J Chem Ecol 18:1337-1347

Tscharntke T, Brandl R (2004) Plant-insect interactions in fragmented landscapes. Annu Rev Entomol 49:405-430

Turner JRG (1988) The evolution of mimicry: a solution to the problem of punctuated equilibrium. In: Brower LP (ed) Mimicry and the evolutionary process. The University of Chicago Press, Chicago, pp 42-66

Watts PC, Hamilton JGC, Ward RD, Noyes HA, Souza NA, Kemp SJ, Feliciangeli D, Brazil R, Maingon RDC (2005) Male sex pheromones and the phylogeographic structure of the Lutzomyia longipalpis species complex (Diptera: Psychodidae) from Brazil and Venezuela. Am J Trop Med Hyg 73(4):734-743

Wcislo WT (1992) Attraction and learning in mate-finding by solitary bees, Lasioglossum (Dialictus) figueresi Wcislo and Nomia triangulifera Vachal (Hymenoptera: Halictidae). Behav Ecol Sociobiol 31:139-148

West-Eberhard MJ (1983) Sexual selection, social competition, and speciation. Q Rev Biol 58:155-183

Wong BBM, Keogh JS, Jennions MD (2004) Mate recognition in a freshwater fish: geographical distance, genetic differentiation, and variation in female preference for local over foreign males. J Evol Biol 17:701-708

Wright S (1943) Isolation by distance. Genetics 28:114-138 